\title{
Current cigarette smoking was associated with a higher risk of Alzheimer's disease
}

\author{
Merchant C, Tang MX, Albert S, et al. The influence of smoking on the risk of Alzheimer's disease. Neurology 1999 Apr \\ 22;52:1408-12.
}

\section{Question}

Is there an association between cigarette smoking and Alzheimer's disease $(\mathrm{AD})$ ?

\section{Design}

Cohort analytic study with follow up for a mean of 2 years.

\section{Setting}

Community based study in northern Manhattan, New York City, USA.

\section{Participants}

1062 elderly Medicare recipients (mean age 75 y, 69\% women) without dementia at start of study.

\section{Assessment of risk factors}

A structured risk factor questionnaire was developed and used at baseline to determine exposure to putative risk factors related to dementia. 3 sets of questions dealt with smoking history. General health and function, years of formal education, and medical history were determined. A physical, neurological, and neuropsychological examination were also done. $A P O E$ genotype was determined for each participant.

\section{Main outcome measure}

Blinded diagnosis of $\mathrm{AD}$ using standardised clinical assessments at annual visits.

\section{Main results}

142 participants were diagnosed with $\mathrm{AD}$ during follow up. After adjustment for education and ethnicity and using never smoked as the reference, a previous history of smoking was not associated with $\mathrm{AD}$ (table). Those who were current smokers had an increased risk of developing $\mathrm{AD}$ (table). The association between current smoking and $\mathrm{AD}$ decreased in the presence of $A P O E \in 4$ but not for current smokers without APOE $\in 4$ (table).

\section{Conclusions}

There was an increased risk of developing Alzheimer's disease among current smokers. APOE $\in 4$ slightly modified this association.

Relative risk (RR) of developing Alzheimer's disease by smoking history

\begin{tabular}{ll}
\hline Tobacco use & Adjusted $R R^{*}(95 \% \mathrm{CI})$ \\
\hline Previous & $0.7(0.5$ to 1.1$) \dagger$ \\
Current & $1.7(1.1$ to 2.8$)$ \\
Current use in APOE $\in 4$ carriers & $1.4(0.6$ to 3.3$) \dagger$ \\
Current use in non-APOE $\in 4$ carriers & $2.1(1.2$ to 3.7$)$ \\
\hline
\end{tabular}

*Multivariate analysis adjusted for education and ethnicity. $†$ Not siginficant

Sources of funding: US Federal Government; the Charles S Robertson Memorial Gift for Alzheimer's Disease from the Banbury Fund; Blanchette Hooke Rockefeller Fund.

For correspondence:Dr R Mayeux, G H Sergievsky Center, 630 West 168th Street, Columbia University, New York, NY 10032 , USA. Fax +12123052518 .

\section{Commentary}

The association between smoking and $\mathrm{AD}$ is controversial. Several early case control studies suggested that smoking is protective against $\mathrm{AD} .{ }^{1}$ Because $\mathrm{AD}$ is associated with reduced acetylcholine activity, perhaps nicotine delays the disease. These studies, however, may be biased because only very fit smokers, with a genetic advantage, survive into later life. ${ }^{2}$ To some extent, this study by Merchant et al and the recently published prospective Rotterdam Study, ${ }^{3}$ have settled the controversy. Both studies found that present smokers are at roughly double the risk of developing $\mathrm{AD}$ than those who have never smoked.

Interestingly, the study by Merchant $e t$ al (but not the Rotterdam Study) found that former smokers may be at a reduced risk (although the result was not statistically significant). Because having an APOE $\in 4$ allele is a risk factor for developing $\mathrm{AD}$ and vascular disease, there may be an interaction between smoking, APOE $\in 4$, and $\mathrm{AD}$. Again, both studies found that smoking is more of a risk factor for those without APOE $\in 4$. This may reflect, however, the fact that smokers with APOE $\in 4$, who survive into later life, are a distinct group.

The main limitation of these studies is that they do not have necropsy confirmation of diagnosis. Smokers may be developing vascular dementia which is misdiagnosed as $\mathrm{AD}$. Also, smoking is a marker for other factors (such as poverty or alcohol use), which Merchant et al have tried to take into account by adjusting for education and ethnicity.
The clinical message is do not recommend smoking to any of your patients, at any age. There is some good news for smokers: giving up smoking reduces your risk of developing $\mathrm{AD}$. The bad news is: otherwise smokers can only reduce their risk of $\mathrm{AD}$ by dying of something else first.

$$
\begin{array}{r}
\text { Rob Butler, MBBS, MRCPsych } \\
\text { Edgeway Community Hospital } \\
\text { Brain Injury Unit } \\
\text { Middlesex, UK }
\end{array}
$$

Lee PN. Smoking and Alzheimer's disease: a review of the epidemiological evidence. Neuroepidemiology 1994;13:131-44.

2 Riggs JE. Smoking and Alzheimer's disease: a protective effect or differential survival bias? Lancet 1993;342:793-4.

3 Ott A, Slooter AJ, Hofman A, et al. Smoking and risk of dementia and Alzheimer's disease in a population-based cohort study: the Rotterdam study. Lancet 1998:351:1840-3. 